\title{
Quantifying the Properties of Low-cost Powder Metallurgy Titanium Alloys
}

\author{
L. Bolzoni ${ }^{*}$, E.M. Ruiz-Navas², E. Gordo ${ }^{2}$ \\ ${ }^{1}$ WaiCAM (Waikato Centre for Advanced Materials), The University of Waikato \\ Private Bag 3105, 3240 Hamilton - New Zealand \\ ${ }^{2}$ Department of Materials Science and Engineering, University Carlos III of Madrid, \\ Avda. de la Universidad, 30, 28911 Leganés, Madrid - Spain \\ *bolzoni.leandro@gmail.com
}

\begin{abstract}
The extensive industrial employment of titanium is hindered by its high production costs where reduction of these costs can be achieved using cheap alloying elements and appropriate alternative processing techniques. In this work the feasibility of the production of low-cost titanium alloys is addressed by adding steel to pure titanium and processing the alloys by powder metallurgy. In particular, a spherical $4140 \mathrm{LCH}$ steel powder commonly used in metal injection moulding is blended with irregular hydride-dehydride Ti. The new low-cost alloys are cold uniaxially pressed and sintered under high vacuum and show comparable properties to other wrought-equivalent and powder metallurgy titanium alloys. Differential thermal analysis and Xray diffraction analyses confirm that $\mathrm{Ti}$ can tolerate the employment of iron as primary alloying element without forming detrimental TiFe-based intermetallic phases. Thus, the newly designed $\alpha+\beta$ alloys could be used for cheaper non-critical components.
\end{abstract}

Keywords: Titanium alloys, powder metallurgy, electron microscopy, mechanical properties, Xray diffraction 


\section{Introduction}

Titanium is the material of choice for high performances components, such as the one applied in the aerospace industry or in biomedicine, due to the combination of physical and mechanical properties it provides. Specifically, titanium has the highest mechanical properties in relation to its density among structural metals, excellent corrosion resistance, good biocompatibility (bioinert) and maintains its mechanical properties at relatively high working temperatures [1-3]. A further expansion of the employment of titanium to mass production industries, such as the automotive, is prevented by its high extraction and production costs (e.g. extraction of titanium from its ores is 15 times and 3 times higher than that of iron and aluminium, respectively) [4]. The high cost of titanium is primarily due to two factors: high affinity for interstitials such as oxygen, nitrogen and carbon that decrease its ductility (i.e. need of particular and expensive processing to limit their contents) and poor machinability as a consequence of its low thermal conductivity [5].

The employment of creative processing techniques, such as powder metallurgy (PM), has been identified as a viable way to reduce the high production costs of titanium [6]. PM techniques have intrinsic advantages on their own with respect to the conventional metallurgical route: they are near-net-shape or net-shape methods (i.e. limited machining required) and have high yield of material utilisation, aspects that are particularly desirable to avoid the production of significant quantities of expensive scraps like chips from machining operations. Furthermore, PM techniques are solid state processes where titanium does not reach the molten state and, consequently, its interaction with the tools, such as ceramic moulds, is less favourable. Finally, the titanium PM industry could take advantage of the latest developments in the field of extraction and production of cheaper powders, such as the Fray-Farthing-Chen (FFC) process [7, 
8]. The actual feasibility of producing titanium parts by PM was primarily assessed in the 1980s by considering wrought-equivalent chemical compositions $[9,10]$. More in detail, the great majority of the works performed focused on the Ti-6Al-4V alloy and showed that comparable static mechanical performances could be obtained. A weakness of many of these studies was the employment of sponge titanium powders directly attained from the Kroll process where residual chlorines were present [11].

Another possible way to reduce the cost of titanium is to use cheaper alloying elements instead of vanadium or niobium to stabilise the body-centred-cubic (B.C.C) $\beta$ phase. Iron has been considered for the development of few low-cost wrought titanium alloys [12-14], such as the Ti5Al-2.5Fe and Ti-1.5Al-5.5Fe-6.8Mo (TIMETAL) alloys, because of its stabilising effect of the $\beta$ phase [15]. Nevertheless, the high density of iron and the formation of TiFe-based brittle intermetallic phases (as per the binary Ti-Fe phase diagram [16]) are important limiting factors for the wrought route. Once again, these limitations could be overcome by using PM techniques where the intrinsic solid state nature of the methods prevents the settlement of heavy iron particles and limits the formation kinetics of the TiFe-based intermetallic phases. In particular, some studies about the development and processing of low-cost iron-containing titanium PM alloys are available in the literature [17-20] but they are rather few and there is still a lack of understanding about the full potential of iron as alloying elements for titanium.

The aim of this work is the investigate the fabrication of low-cost $\alpha+\beta$ titanium alloys by considering the combined advantages of the cheapest PM method (i.e. uniaxial pressing and sintering) and using iron as mayor alloying elements. Specifically, a commercially available 4140 LHC steel powder with spherical morphology is added to pure hydride-dehydride (HDH) titanium. The 4140 LHC steel powder was chosen because it is mainly constituted of iron, which 
is intended to be used as primary alloying element for titanium. Moreover, the 4140 LHC steel powder has a spherical morphology and a much finer particle size in comparison to the angular HDH pure titanium powder. The fine particle size and the spherical morphology should accelerate the diffusion of iron towards the titanium lattice and increase the densification of the material, respectively.

\section{Experimental Procedure}

The materials acquired for this study are an irregular elemental titanium powder $(\mathrm{Ti}>99.6 \%,<$ $75 \mu \mathrm{m}$, GfE GmbH/Germany) produced via the comminution HDH process and a gas atomised spherical 4140 steel powder $(0.95 \mathrm{Cr}-0.875 \mathrm{Mn}-0.2 \mathrm{Cr}-0.4 \mathrm{C}-97.3 \mathrm{Fe}, \quad<27 \mu \mathrm{m}$, Sandvik $\mathrm{AB} / \mathrm{Sweden})$. The targeted low-cost titanium alloys compositions were chosen on the base of a previous study where optimum addition of iron was found to be between 5 wt.\% and 7 wt.\% [19]. Specifically, the formula proposed by Molchanova [21], to quantify the total effect of the $\beta$ stabiliser elements $\left([\mathrm{Mo}]_{\mathrm{eq}}=\right.$ molybdenum equivalent parameter $)$ was used: $[\mathrm{Mo}] \mathrm{eq} .=[\mathrm{Mo}]+$ $0.67[\mathrm{~V}]+1.25[\mathrm{Cr}]+1.25[\mathrm{Ni}]+1.7[\mathrm{Mn}]+1.7[\mathrm{Co}]+2.5[\mathrm{Fe}]$. The $[\mathrm{Mo}]$ eq. parameter of 12.5 and 17.5 which, respectively, correspond to the binary $\mathrm{Ti}-5 \mathrm{Fe}$ and $\mathrm{Ti}-7 \mathrm{Fe}$ respectively, were used to devise the Ti-5.1\%(4140) and the Ti-7.1\%(4140) alloys. Some relevant features of the Ti$5.1 \%(4140)$ and the Ti-7.1\%(4140) starting powders are shown in Table 1 where the density of the Ti-5.1\%(4140) and the Ti-7.1\%(4140) starting powders was calculated with the rule of mixtures. Particle size analysis was done in a Mastersizer/2000 laser beam analyser. Oxygen and nitrogen percentages, of both powders and sintered samples, were measured with a LECO TC500 as per ASTM:E1409 [22]. The density of the Ti-5.1\%(4140) and the Ti-7.1\%(4140) alloys is higher than that of titanium $\left(4.51 \mathrm{~g} / \mathrm{cm}^{3}\right)$, due to higher density of iron, and increases 
with the 4140 LHC steel content. The particle size of the starting powders is lower than $90 \mu \mathrm{m}, \mathrm{a}$ common value for powders to be processed by uniaxial pressing.

Table 1. Features of the Ti-5.1\%(4140) and Ti-7.1\%(4140) starting powders.

\begin{tabular}{|c|c|c|c|}
\hline \multirow{2}{*}{ Features } & \multicolumn{2}{c|}{ Material } \\
\cline { 3 - 4 } & & $T i-5.1 \%(4140)$ & Ti-7.1\%(4140) \\
\hline \hline \multicolumn{2}{|c|}{ Density $\left(\rho_{\text {th. }}\right)\left[\mathrm{g} / \mathrm{cm}^{3}\right]$} & 4.68 & 4.75 \\
\hline \multirow{2}{*}{ Particle size analysis $[\mu \mathrm{m}]$} & $\mathrm{D}_{50}$ & 46.52 & 47.14 \\
\cline { 3 - 4 } & $\mathrm{D}_{90}$ & 86.91 & 87.50 \\
\hline \hline \multirow{4}{*}{ Chemical composition $[w t . \%]$} & $\mathrm{Ti}$ & Balance & Balance \\
\cline { 2 - 4 } & $\mathrm{Fe}$ & 4.98 & 6.97 \\
\cline { 2 - 4 } & $\mathrm{O}$ & 0.24 & 0.22 \\
\cline { 2 - 4 } & $\mathrm{N}$ & 0.056 & 0.058 \\
\cline { 2 - 4 } & $\mathrm{Cr}$ & 0.05 & 0.07 \\
\cline { 2 - 4 } & $\mathrm{Mn}$ & 0.04 & 0.06 \\
\cline { 2 - 4 } & $\mathrm{Mo}$ & 0.01 & 0.01 \\
\hline
\end{tabular}

The Ti-5.1\%(4140) and Ti-7.1\%(4140) powders were cold uniaxially pressed (zinc stearate lubricated floating die) in the compaction range of $300-700 \mathrm{MPa}$ to determine their compressibility (ASTM:B331) [23] and green strength (ASTM:B312) [24]. Samples with dimensions as per (ASTM:B528) [25] were pressed at $700 \mathrm{MPa}$ for further processing. A differential thermal analysis (DTA) scan of the green samples was initially carried out up to $1400^{\circ} \mathrm{C}$ (heating rate of $10^{\circ} \mathrm{C} / \mathrm{min}$ under a flow of inert atmosphere of Ar) to assess whether TiFe-based intermetallic phases would form during sintering. The specimens were sintered in the sintering window of $900-1300^{\circ} \mathrm{C}$ during 60 minutes in high vacuum atmosphere $\left(10^{-5}\right.$ mbar $)$ using $5^{\circ} \mathrm{C} / \mathrm{min}$ for heating and cooling. The sintering temperature of $900^{\circ} \mathrm{C}$ was chosen to assess whether a low sintering temperature would be sufficient to promote the complete diffusion of the alloying elements whilst $1200-1300^{\circ} \mathrm{C}$ are common sintering temperatures for titanium [21, 2628]. 
SiC papers grinding, silica gel polishing and Kroll reactant etching was the metallographic route employed for the SEM-EDS characterisation (Philips XL30). The identification of the phases that compose the Ti-5.1\%(4140) and Ti-7.1\%(4140) alloys was further confirmed by means of X-ray diffraction (XRD) analysis (Philips X'Pert). The parameters set were: 2-Theta range between $30^{\circ}$ and $80^{\circ}, 0.02^{\circ}$ goniometer step and $1.2 \mathrm{~s}$ step time. The dimensions and the weight of the samples were used to obtain the green density $\left(\rho_{g r}\right)$. Water displacement measurements were done to determine the density of the sintered samples $\left(\rho_{\text {sint. }}\right)$ from which the relative density $\left(\rho_{\text {rel. }}=\rho_{\text {sint. }} / \rho_{\text {th. }}\right)$ was calculated using the theoretical values $\left(\rho_{t h .}\right)$ of the Ti-5.1\%(4140) and Ti7.1\%(4140) alloys reported in Table 1 . The mechanical characterisation included three-point bending tests (as per ASTM:B528) [25]) carried out using a MicroTest equipment and Vickers hardness (HV30) measured in a universal tester (Wilson Wolpert). It is worth mentioning that at least three samples were considered to measure and calculate the properties of the low-cost $\alpha+\beta$ Ti-5.1\%(4140) and Ti-7.1\%(4140) alloys.

\section{Results and Discussion}

The low-cost Ti-5.1\%(4140) and Ti-7.1\%(4140) alloys were designed to be processed by cold uniaxial pressing to limit their cost. Consequently, an $\mathrm{HDH}$ elemental titanium powder with irregular morphology was chosen as base material to provide good compressibility and sufficiently high green strength necessary for the handling of the samples [29, 30]. The 4140 LHC steel powder, which is characterised by much finer particle size, was chosen to favour the diffusion of the alloying elements onto titanium as well as the densification of the alloy. The powder selected to add the alloying elements should not jeopardise the compressibility and the strength of the base materials (i.e. $86 \%$ and $11 \mathrm{MPa}$, respectively, when shaping the powder at 
$700 \mathrm{MPa}$ ). This is actually the case as it can be seen in Figure 1 where the trends of the compressibility and green strength of the Ti-5.1\%(4140) and Ti-7.1\%(4140) powders are shown. Specifically, the green density of both low-cost titanium powders increases with the compacting pressure reaching values comparable to that of the base material at $700 \mathrm{MPa}$. There is, in fact, an influence of the addition of the fine 4140 LHC powder as well as of the relative volumetric amount of spherical particles but it is mainly significant at low shaping pressure. The presence of the 4140 LHC powder particles, which are harder than titanium, leads to some increment of the green strength, property that also increases along with the increment of the compacting pressure. In the case of the strength, the addition rate has a constant effect throughout the whole spectrum of shaping pressure because the Ti-7.1\%(4140) pressed powder has always slightly higher strength with respect to the Ti-5.1\%(4140) powder.

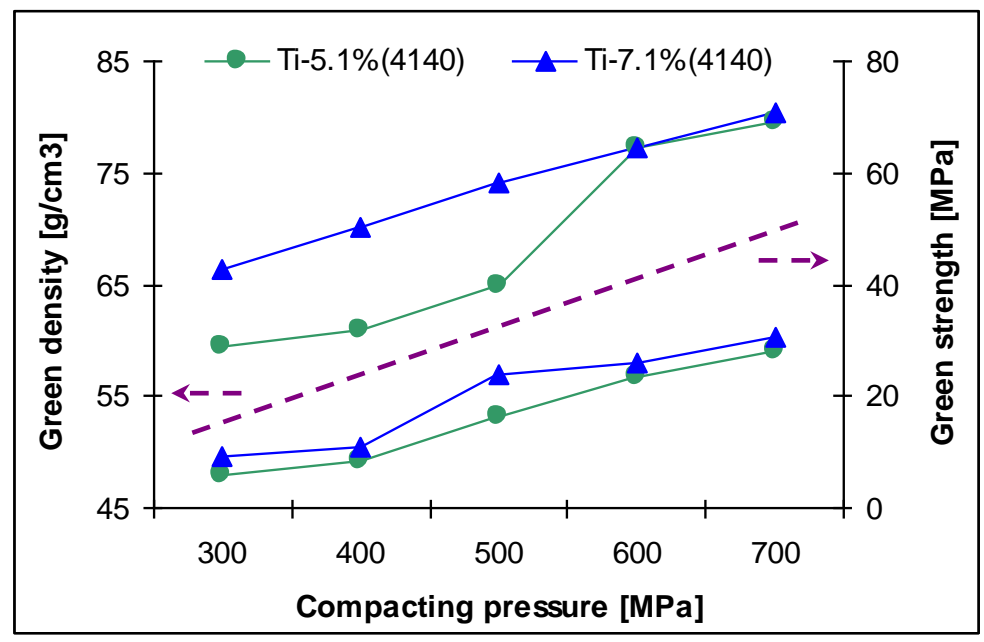

Figure 1. Green density (i.e. compressibility) and green strength versus compacting pressure for the Ti-5.1\%(4140) and Ti-7.1\%(4140) powders.

The chemical composition of the low-cost Ti-5.1\%(4140) and Ti-7.1\%(4140) alloys was designed to prevent the possible formation of TiFe-based intermetallic phases (which should 
form on the base of the binary Ti-Fe phase diagram [16]), by calibrating the addition rate of the 4140 LHC steel powder and considering the kinetics of formation of these intermetallic phases. The results of the DTA analysis displayed in Figure 2 confirms that there is no formation of any TiFe-based compounds during the sintering of the low-cost titanium alloys as only one endothermic peak was detected in the DTA analysis of both alloys. The peak of this transformation is around $880^{\circ} \mathrm{C}$ indicating that is the allotropic transformation of titanium from the hexagonal $\alpha$-Ti phase to the cubic $\beta$-Ti phase. Due to the endothermic nature of the allotropic transformation the material requires thermal energy for the phase change which takes places at the temperature of elemental titanium (i.e. $882^{\circ} \mathrm{C}[31]$ ) because the alloying elements (i.e. $\beta$ stabilisers) are not dissolved inside the matrix yet.

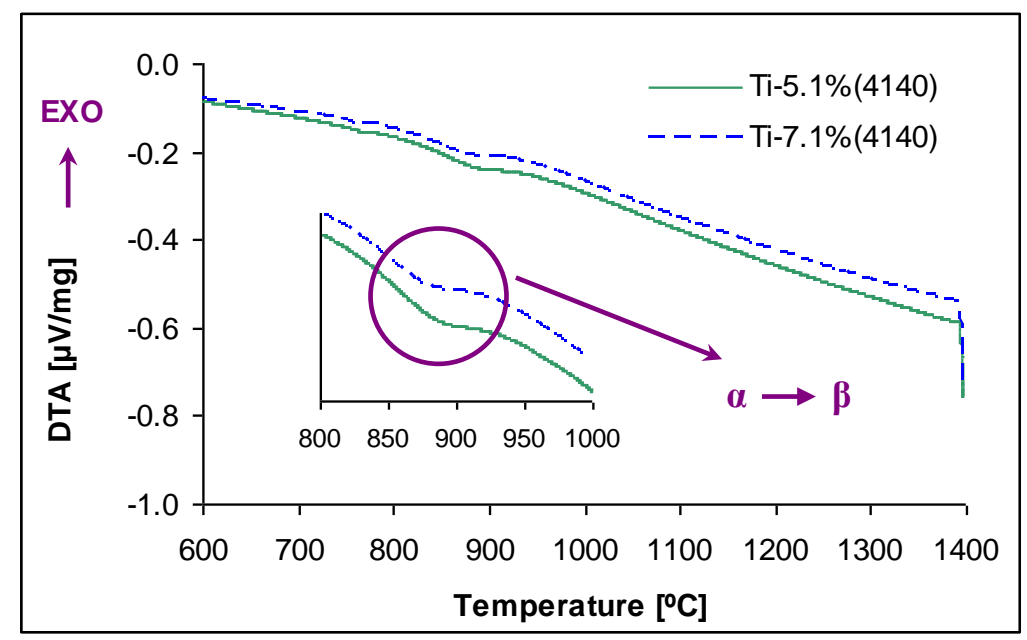

Figure 2. DTA heating curves of the Ti-5.1\%(4140) and Ti-7.1\%(4140) alloys.

The addition rate of 4140 LHC powder was chosen to design low-cost $\alpha+\beta$ titanium alloys where the mayor elements composing the steel powder (i.e. Fe, Cr, Mn and Mo) are all stabilising the cubic $\beta$-Ti phase. Microstructural analysis of the sintered Ti-5.1\%(4140) and Ti-7.1\%(4140) alloys, whose result are presented in Figure 3, reveals that the alloys are characterised by the 
typical microstructure of $\alpha+\beta$ titanium alloys slow cooled from a processing temperature above the $\beta$ transus [31]. An exception are the samples sintered at $900^{\circ} \mathrm{C}$ (Figure $3 \mathrm{a}$ and $\mathrm{b}$ ) because their microstructure is not fully homogeneous and some small undissolved 4140 LHC steel particles are present. The inhomogeneous microstructure of the materials sintered at $900^{\circ} \mathrm{C}$ indicates that this sintering temperature is not high enough to promote the complete diffusion of the alloying elements and that most of the thermal energy is spent in homogenising and not densifying the alloy. Nonetheless, the homogenisation is much more pronounced than in the case of $\mathrm{Al}: \mathrm{V}$ master alloy [32] due to the fine particle size of the 4140 LHC powder chosen and the high diffusion rate of iron onto the titanium lattice [33, 34]. Consequently, the microstructure of the materials sintered at $900^{\circ} \mathrm{C}$ is composed of grains of the $\alpha$-Ti phase and $\alpha+\beta$ lamellae where $\beta$-Ti phase is present due to the stabilising effect of the alloying elements, especially iron. The poor densification of the low-cost titanium alloys sintered at $900^{\circ} \mathrm{C}$ is confirmed by the amount and shape of the residual porosity, which is highly irregular and primarily interconnected. Furthermore, some of the boundaries of the base elemental titanium powder are still present. When the low-cost $\mathrm{Ti}-5.1 \%(4140)$ and $\mathrm{Ti}-7.1 \%(4140)$ alloys are sintered at $1200^{\circ} \mathrm{C}$ the chemical composition is fully homogeneous throughout the whole microstructure (Figure $3 \mathrm{c}$ and d). At this stage the residual porosity is mainly isolated and tending to be spherical in shape even if there are still some irregular pores. The increment of the sintering temperature to $1300^{\circ} \mathrm{C}$ does not alter the nature of the phases present but induces both grain growth and residual porosity reduction, where the size of the pores increases and the shape is principally spherical (Figure $3 \mathrm{e}$ and f). It is worth mentioning that during the microstructural analysis no TiFe-based intermetallic phases were found regardless of the processing temperature used to sinter the alloys, in agreement with the DTA results shown in Figure 2. By comparing the microstructure of the two 
low-cost titanium alloys, the Ti-7.1\%(4140) alloy is, in general, characterised by lower volumetric amount of residual porosity (approximately $0.3 \%$ ) and coarser microstructural features. The size of the prior $\beta$-Ti grains from which the $\alpha$ grains and $\alpha+\beta$ lamellae originate and grow are smaller for the Ti-5.1\%(4140) alloy $(71 \pm 9 \mu \mathrm{m}$ and $97 \pm 12 \mu \mathrm{m}$ for the materials sintered at $1200^{\circ} \mathrm{C}$ and $1300^{\circ} \mathrm{C}$, respectively) than for the Ti-7.1\%(4140) alloy $(98 \pm 8 \mu \mathrm{m}$ and $121 \pm 18 \mu \mathrm{m}$ for the materials sintered at $1200^{\circ} \mathrm{C}$ and $1300^{\circ} \mathrm{C}$, respectively). The interlamellar spacing should decrease with the increment of iron as found by Chen et al. [20].
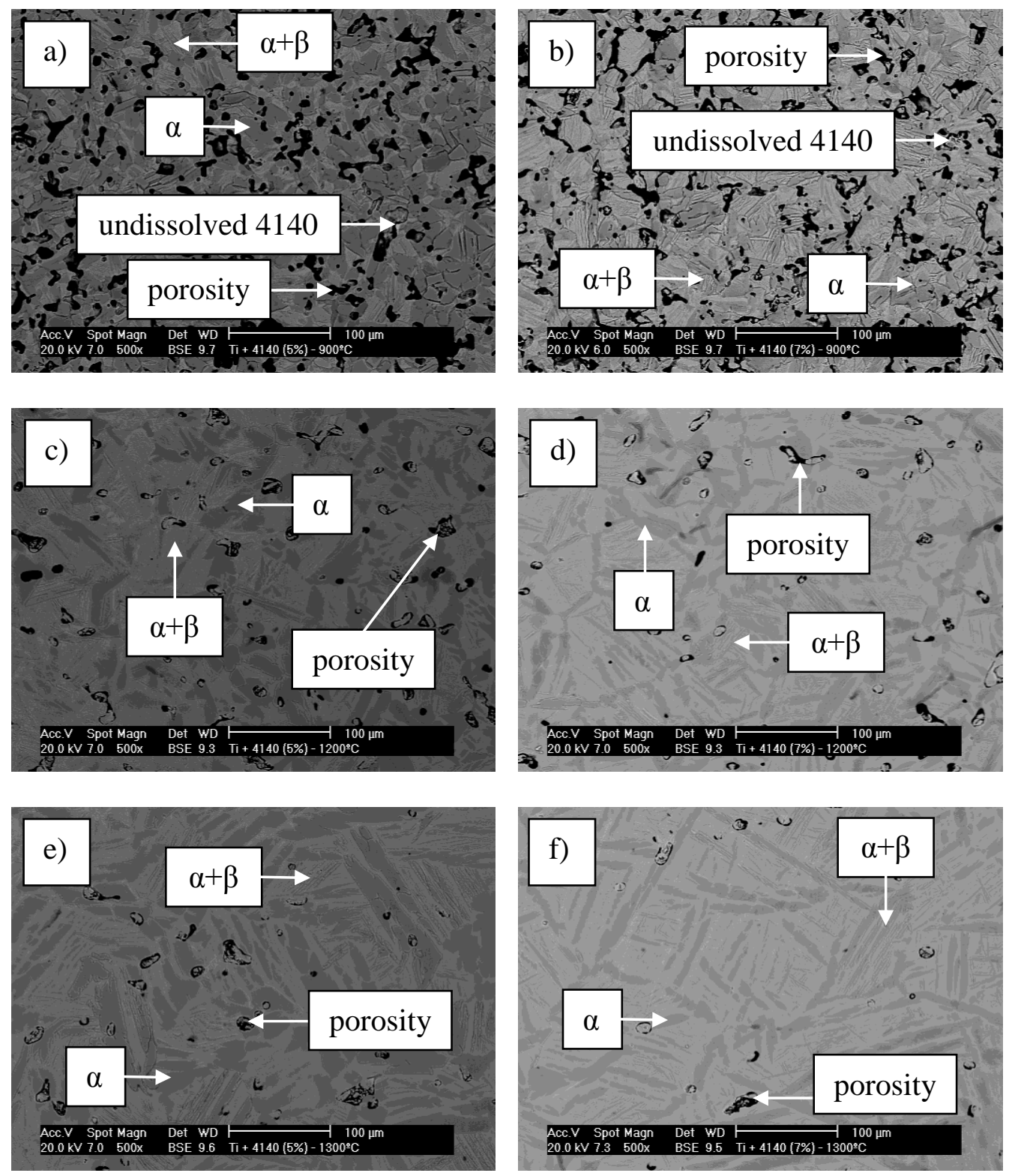
Figure 3. SEM micrographs of the Ti-5.1\%(4140) and Ti-7.1\%(4140) alloys, left and right respectively, sintered at: a) and b) $900^{\circ} \mathrm{C}$, c) and d) $1200^{\circ} \mathrm{C}$ and e) and f) $1300^{\circ} \mathrm{C}$.

The low-cost Ti-5.1\%(4140) and Ti-7.1\%(4140) alloys were designed to be $\alpha+\beta$ titanium alloys and the formation of detrimental TiFe-based intermetallic phases was prevented as discussed on the base of the DTA (Figure 2) and microstructural characterisation (Figure 3). A further prove of the nature of the phases composing the low-cost titanium alloys are the results of the XRD analysis shown in Figure 4 where, independently of the total amount of $\beta$ stabilisers added and of the sintering temperature employed, the only phases detected on the two low-cost titanium alloys are the $\alpha$-Ti and the $\beta$-Ti phases.

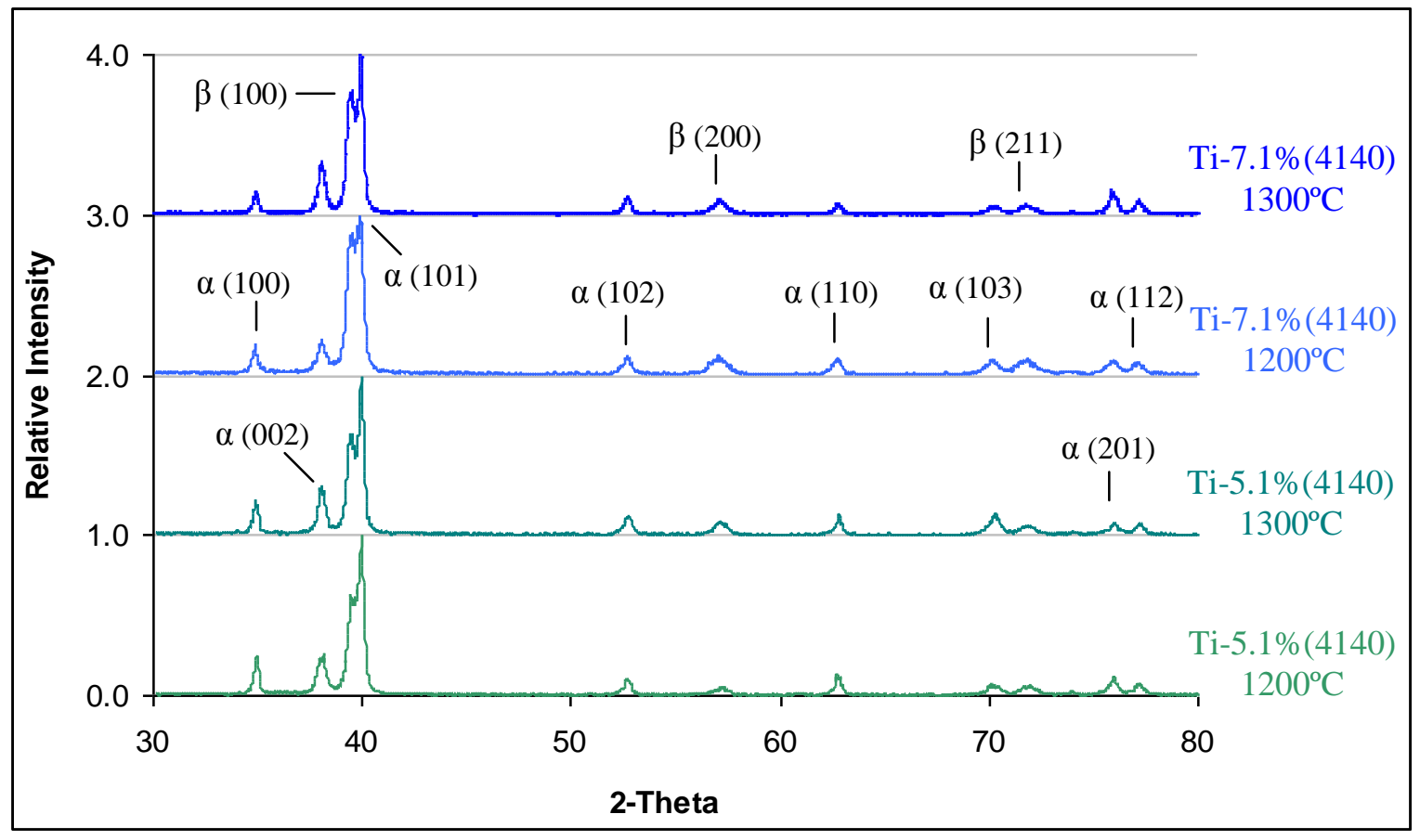

Figure 4. XRD patterns $\left(2-\right.$ Theta $\left.=30-80^{\circ}\right)$ of the Ti-5.1\%(4140) and Ti-7.1\%(4140) alloys sintered at $1200^{\circ} \mathrm{C}$ and $1300^{\circ} \mathrm{C}$. 
Specifically, three $\beta$-Ti peaks (i.e. 100, 200 and 211) were found. When comparing the two alloys, it can be seen that the intensity of the $\beta$-Ti peaks is higher for the Ti-7.1\%(4140) alloy confirming the greater amount of $\beta$ phase present in this alloy. XRD analysis further proves that the formation of brittle TiFe-based intermetallic phases is prevented when $\alpha+\beta$ titanium alloys developed on the base of iron addition are fabricated using the pressing and sintering PM route as not peaks related to TiFe-based intermetallic phases were detected.

The sintering of the low-cost Ti-5.1\%(4140) and Ti-7.1\%(4140) green compacts induces their densification and, thus, their shrinkage as it is shown in Figure 5. In particular, it can be seen that both the shrinkage and the densification of the low-cost titanium alloys increase along with the sintering temperature but, actually, the greatest variation takes place when the processing temperature is raised from $900^{\circ} \mathrm{C}$ to $1200^{\circ} \mathrm{C}$.

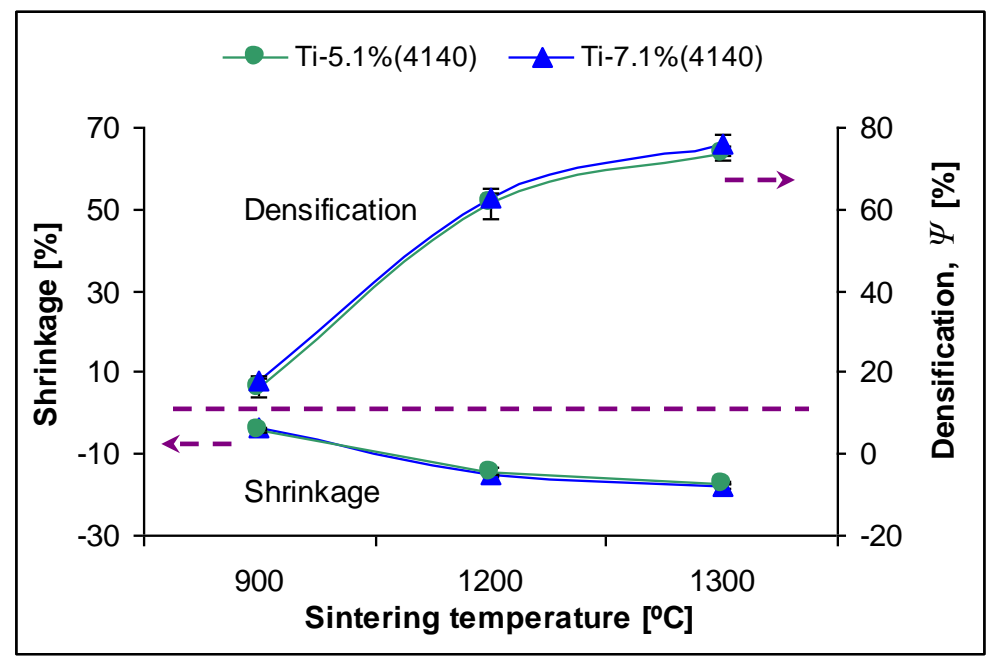

Figure 5. Shrinkage and densification versus sintering temperature for the Ti-5.1\%(4140) and Ti-7.1\%(4140) alloys.

This behaviour could be expected on the base of the results of the microstructural analysis (Figure 3) where it was already detected that at low sintering temperature the thermal energy is 
mainly spent in diffusion of the alloying elements and not in the densification of the materials. Similar absolute values in between $4-18 \%$ for the shrinkage and $20-75 \%$ for the densification when using a sintering temperature window of $900-1300^{\circ} \mathrm{C}$ were obtained when alloying titanium with an 430 stainless steel powder [19] with comparable particle size to that of the 4140 LHC powder used in this study. Consequently, it can be concluded that the shrinkage and densification greatly depend on the size of the powder used to add the $\beta$ stabilisers rather than in the nature of the powder itself.

In Figure 1 it was shown that the Ti-5.1\%(4140) and Ti-7.1\%(4140) alloys have similar green density when shaped at $700 \mathrm{MPa}$, but the Ti-7.1\%(4140) alloy always has slightly higher shrinkage and densification compared to the Ti-5.1\%(4140) alloy. This difference is due to the relative amount of spherical 4140 LHC powder added in each specific case. Because of its higher densification, the Ti-7.1\%(4140) alloy is also characterised by somewhat higher $(\sim 0.3 \%)$ sintered relative density with respect to the Ti-5.1\%(4140) alloy as visible in Figure 6.

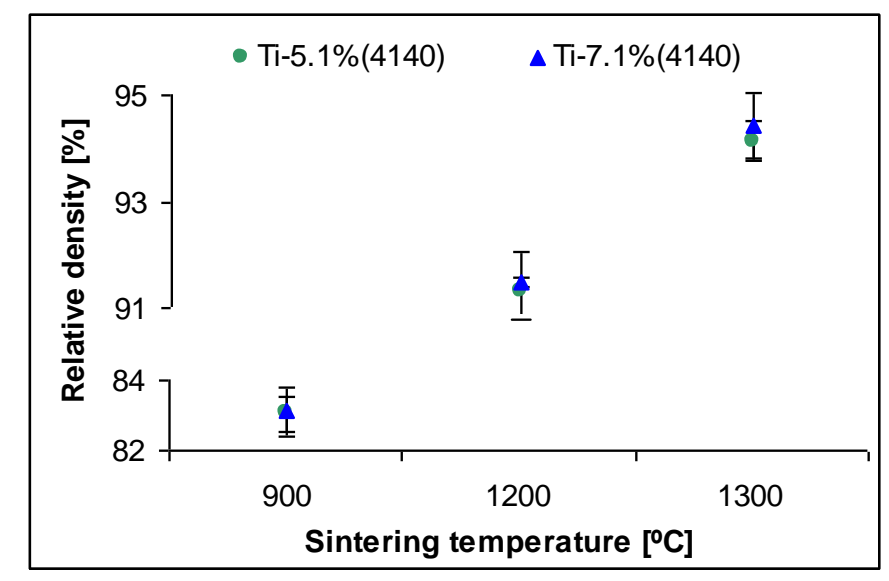

Figure 6. Relative density versus sintering temperature for the Ti-5.1\%(4140) and Ti7.1\%(4140) alloys. 
The increment of the relative density with the sintering temperature of the Ti-5.1\%(4140) and Ti$7.1 \%(4140)$ alloys is the expected trend for irregular powder processed by cold uniaxial pressing and sintering. Concordantly with the data shown in Figure 5, the greatest increment of the relative density of the low-cost alloys is found between $900^{\circ} \mathrm{C}$ and $1200^{\circ} \mathrm{C}$. The final values of the relative density in the $1200-1300^{\circ} \mathrm{C}$ sintering temperature window are comparable to those of other wrought-equivalent titanium alloys such as Ti-3Al-2.5V [26] and Ti-6Al-4V [35-37] alloys.

The total amount of interstitial elements dissolved inside the titanium lattice greatly affects the mechanical response of the material as systematic studies have demonstrated that the greater the amount of oxygen and nitrogen the stronger, the harder and the more brittle titanium becomes [38-40]. Titanium normally requires special processes for its fabrication, many of which are carried out under vacuum or inert atmosphere. Even though of this precaution, interstitial pick-up can occur due to the interaction of titanium with oxide- and nitride-based processing tools or due to the atoms adsorbed into titanium particles, which is especially relevant for this work. The handling and the shaping of the powder in atmosphere lead to some increment of the interstitials dissolved although sintering is carried out under high vacuum. This is also the case for the lowcost Ti-5.1\%(4140) and Ti-7.1\%(4140) alloys whose contents of oxygen and nitrogen are reported in Table 2 showing that there is an important oxygen pick-up when sintering the lowcost titanium alloys with respect to the amount of the starting powders (Table 1) whilst the nitrogen content is not that significantly changed. Independently of the alloy composition and processing parameters the total amount of dissolved oxygen is approximately $0.50 \mathrm{wt} . \%$. 
Table 2. Oxygen and nitrogen contents of the sintered low-cost Ti-5.1\%(4140) and Ti$7.1 \%(4140)$ alloys.

\begin{tabular}{|c|c|c|c|c|}
\hline Alloy & \multicolumn{2}{|c|}{ Ti-5.1\%(4140) } & \multicolumn{2}{c|}{ Ti-7.1\%(4140) } \\
\hline Interstitial element & $O[w t . \%]$ & $N[w t . \%]$ & $O[w t . \%]$ & $N[w t . \%]$ \\
\hline $1200^{\circ} \mathrm{C}$ & $0.51 \pm 0.05$ & $0.061 \pm 0.030$ & $0.50 \pm 0.08$ & $0.069 \pm 0.004$ \\
\hline $1300^{\circ} \mathrm{C}$ & $0.50 \pm 0.05$ & $0.088 \pm 0.011$ & $0.49 \pm 0.06$ & $0.071 \pm 0.003$ \\
\hline
\end{tabular}

The representative load-deformation curves of the Ti-5.1\%(4140) and Ti-7.1\%(4140) alloys reported in Figure 7a) show that these low-cost titanium alloys have a purely flexural elastic behaviour without deforming plastically before rupture. Furthermore, independently of the composition and the sintering conditions, the low-cost titanium alloys have similar elastic modulus as it is found that their load-deformation curves overlap. The increment of the sintering temperature has an opposite effect on the strength of the materials because this property increases for the Ti-5.1\%(4140) alloy but decreases for the Ti-7.1\%(4140) when the sintering temperature is raised from $1200^{\circ} \mathrm{C}$ to $1300^{\circ} \mathrm{C}$ as the strength/strain to fracture data reported in Figure $7 \mathrm{~b}$ show. A higher sintering temperature also decreases the ability to deform under the applied load. Generally, the Ti-5.1\%(4140) alloy has better overall mechanical performances with respect to the $\mathrm{Ti}-7.1 \%(4140)$ alloy. Nevertheless, the Ti-7.1\%(4140) alloy sintered at $1300^{\circ} \mathrm{C}$ has a comparable combination of mechanical properties to that of the $\mathrm{Ti}-5.1 \%(4140)$ alloy sintered at $1200^{\circ} \mathrm{C}$ as they have similar grain size. The slightly higher densification experienced by the Ti-7.1\%(4140) alloy combined with the more significant coarsening of the microstructural features with the sintering temperature indicate that this alloy reaches the final stage of sintering earlier. Coarser prior $\beta$ grains and bigger residual porosity account for the lower mechanical properties of this alloy. The fracture before undergoing plastic deformation is due to the relatively high interstitials contents in comparison to the limit for wrought $\alpha+\beta \mathrm{Ti}$ 
alloys (generally $0.20 \mathrm{wt} . \%$ for oxygen and $0.05 \mathrm{wt} . \%$ for nitrogen [31]). With the main exception of the $\mathrm{Ti}-7.1 \%(4140)$ alloy sintered at $1300^{\circ} \mathrm{C}$, the low-cost titanium alloys studied have comparable or higher strength with respect to wrought biomedical devices made out of the Ti-6Al-4V (903-1090 MPa) and Ti-6Al-7Nb (935-995 MPa) alloys [41].
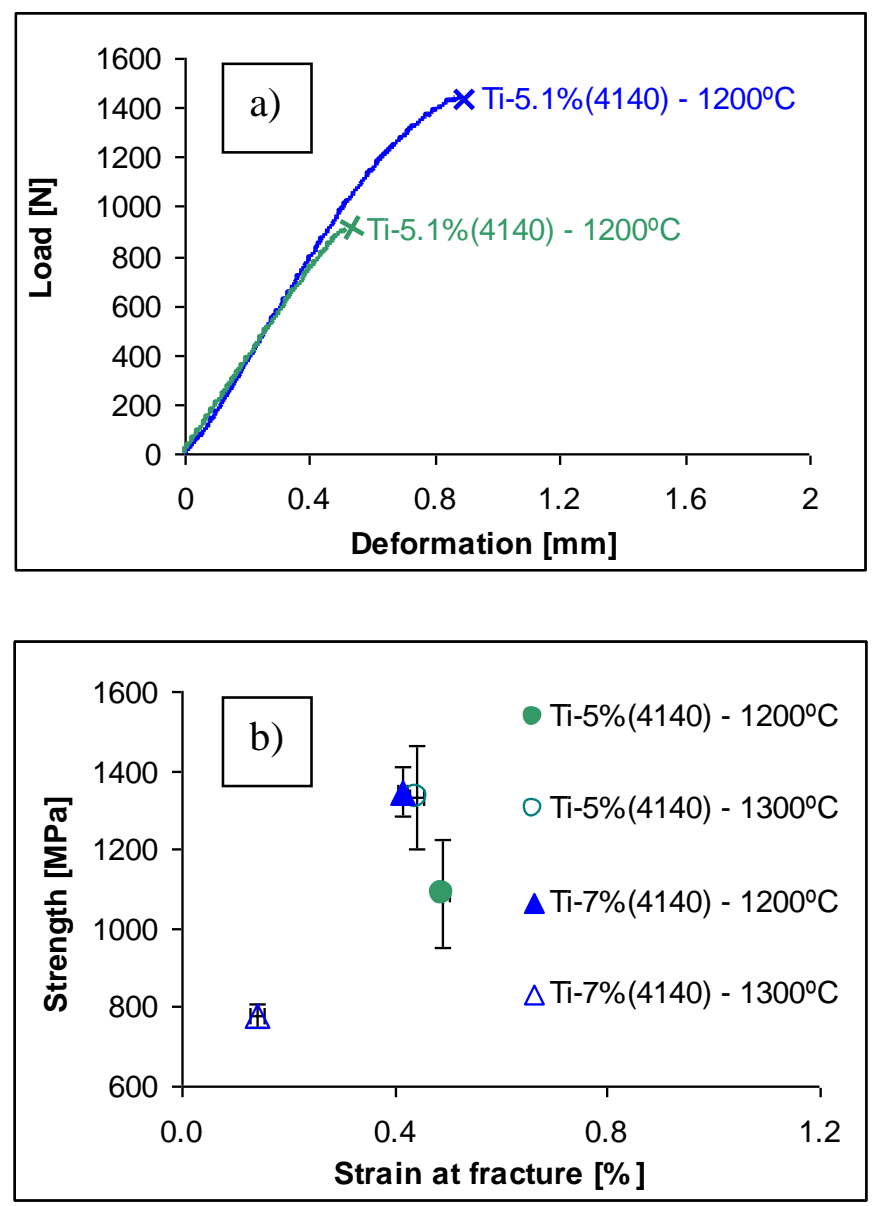

Figure 7. Representative three-point bending load-deformation curves (a) and strength/strain to fracture data of the Ti-5.1\%(4140) and Ti-7.1\%(4140) alloys (b).

The low-cost Ti-5.1\%(4140) and Ti-7.1\%(4140) alloys are $\alpha+\beta$ titanium alloy and, therefore, are expected to have comparable mechanical behaviour to that of the Ti-6Al-4V alloy. From Figure 8 it can actually be seen that the low-cost titanium alloys have similar Vickers hardness to the Ti- 
$6 \mathrm{Al}-4 \mathrm{~V}$ alloy with the exception of the samples sintered at $900^{\circ} \mathrm{C}$. The relatively low hardness of the latest materials is due to the presence of a significant amount of irregular and interconnected open residual porosity as one of their microstructural feature. From Figure 8 it can also be noticed that the hardness of the sintered low-cost alloys increases with the sintering temperature or, in turns, with the reduction and spheroidisation of the residual porosity. This behaviour is quite common for pressed and sintered materials where the mechanical performances increase with the increment of the relative density. From the analysis of the Vickers hardness measurements the effect of the relative amount of $\beta$ stabilisers (i.e. percentage of alloying elements) can be clearly seen. Specifically, the Ti-7.1\%(4140) alloy is always characterised by higher hardness values with respect to the Ti-5.1\%(4140) alloy. As the two low-cost titanium alloys share similar densification behaviour, relative density and amount of interstitials, the average difference of $30 \mathrm{HV}$ is the direct consequence of the total amount of alloying elements, and the associated microstructures (i.e. coarser microstructural features of the Ti-7.1\%(4140) alloy), and the interstitials contents. This last factor also explains the comparable hardness of the low-cost alloys with respect to the wrought Ti-6Al-4V alloy (annealed), which is fully-dense (i.e. without porosity) but has a maximum oxygen content of $0.2 \mathrm{wt} \%$ [31], but similar microstructure as all the were slow cooled from above their $\beta$ transus.

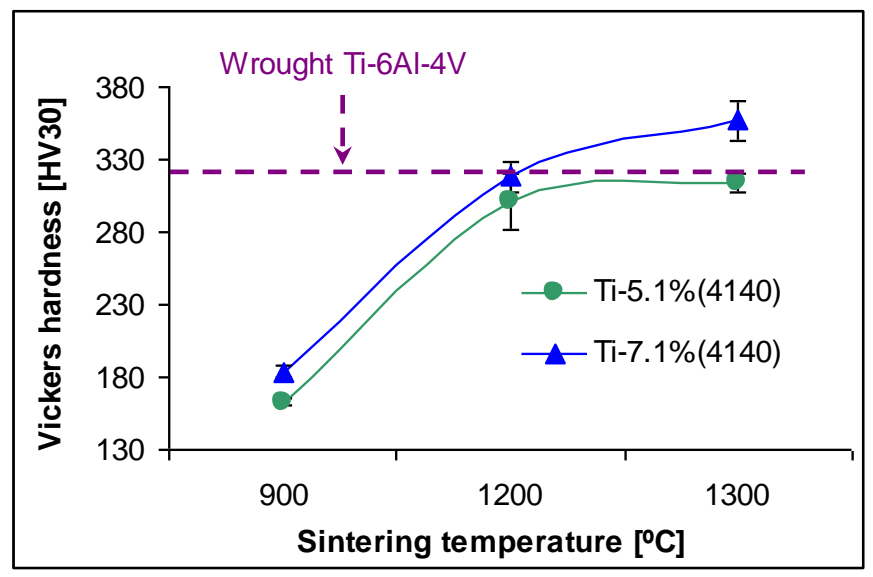


Figure 8. Vickers hardness versus sintering temperature for the Ti-5.1\%(4140) and Ti$7.1 \%(4140)$ alloys.

\section{Conclusions}

The designed low-cost $\alpha+\beta$ titanium alloys obtained from the addition of 4140LHC steel powder and processed by cold uniaxial pressing and sintering show good compressibility and strength to be handled without problem. The employment of fine powders for the addition of $\beta$ stabilisers enhances the densification of the materials and the homogenisation of the alloying elements so that comparable relative density values to those of wrought-equivalent powder metallurgy alloys are obtained. The utilisation of iron as alloying element contributes to reduce the cost of the material and its calibrated design permits to prevent the formation of brittle TiFe-based intermetallic phases. Under appropriate sintering conditions the low-cost titanium alloys have similar mechanical performances to those of wrought $\alpha+\beta$ titanium alloys used in biomedical devices even though of the presence of some residual porosity. Consequently, non-critical components could be made out of the low-cost $\alpha+\beta$ titanium alloys with reduced production costs in comparison to conventional wrought alloys.

\section{Acknowledgements}

The authors want to acknowledge the financial support from New Zealand Ministry of Business, Innovation and Employment (MBIE) through the TiTeNZ (Titanium Technologies New Zealand) UOWX1402 research contract.

\section{References}


[1] I.J. Polmear, Light Alloys. From Traditional Alloys to Nanocrystals, $4^{\text {th }}$ ed., ButterworthHeinemann, UK, 2006.

[2] C. Leyens, M. Peters, Titanium and Titanium Alloys. Fundamentals and Applications, WileyVCH, Köln, Germany, 2003.

[3] V.A. Joshi, Titanium Alloys: An Atlas of Structures and Fracture Features, Taylor \& Francis, NW, U.S.A., 2006.

[4] K. Faller, F.S. Froes, The Use of Titanium in Family Automobiles: Current Trends, JOM 53(4) (2001) 27-28.

[5] R.I. Jaffee, The Physical Metallurgy of Titanium Alloys, Progress in Metal Physics 7 (1958) 65-163.

[6] F.H. Froes, M.N. Gungor, M.A. Imam, Cost-affordable Titanium: The Component Fabrication Perspective, JOM 59(6) (2007) 28-31.

[7] G.Z. Chen, D.J. Fray, T.W. Farthing, Direct Electrochemical Reduction of Titanium Dioxide to Titanium in Molten Calcium Chloride, Nature 407 (2000) 361-364.

[8] D. Fray, Metalysis Leads Charge for Change in Titanium Production, Metal Powder Report 64(9) (2009) 6-11.

[9] P.J. Andersen, P.C. Eloff, Development of Higher Performance Blended Elemental Powder Metallurgy Ti Alloys, in: F.H. Froes, J.E. Smugeresky (Eds.) Powder Metallurgy of Titanium Alloys, The Metallurgical Society of AIME, Las Vegas, Nevada, 1980, pp. 175-187.

[10] G. Welsch, Y.-T. Lee, P.C. Eloff, D. Eylon, F.H. Froes, Deformation Behaviour of Blended Elemental Ti-6Al-4V Compacts, Metallurgical and Materials Transactions A 14(3) (1983) 761769. 
[11] F.H. Froes, S.J. Mashl, V.S. Moxson, J.C. Hebeisen, V.A. Duz, The Technologies of Titanium Powder Metallurgy, JOM 56(11) (2004) 46-48.

[12] D.J. Lin, C.P. Ju, J.H.C. Lin, Structure and Properties of Cast Ti-Fe Alloys, Transactions of the American Foundrymen's Society, 107 (1999) 859-864.

[13] F.C. Holden, H.R. Ogden, R.I. Jaffee, Heat Treatment and Mechanical Properties of Ti-Fe Alloys, Transactions of the American Institute of Mining and Metallurgical Engineers 206(5) (1956) 521-528.

[14] D.B. Lee, K.B. Park, H.W. Jeong, S.E. Kim, Mechanical and Oxidation Properties of TixFe-ySi Alloys, Materials Science and Engineering A 328(1-2) (2002) 161-168.

[15] G. Lütjering, J.C. Williams, Titanium: Engineering Materials and Processes, $1^{\text {st }}$ ed., Springer, Manchester, UK, 2003.

[16] J.L. Murray, Phase Diagrams of Binary Titanium Alloys, $1^{\text {st }}$ ed., ASM International, Ohio, USA, 1987.

[17] K. Majima, T. Hirata, M. Yamamoto, H. Nagai, K. Shouji, Microstructures and Tensile Properties of Hot Isostatically Pressed Ti-Fe Alloys, Journal of the Japan Institute of Metals 52(11) (1988) 1113-1120.

[18] O.M. Ivasishin, Cost-effective Manufacturing of Titanium Parts with Powder Metallurgy Approach, Materials Forum 29 (2005) 1-8.

[19] L. Bolzoni, E. Herraiz, E.M. Ruiz-Navas, E. Gordo, Study of the Properties of Low-cost Powder Metallurgy Titanium Alloys by 430 Stainless Steel Addition, Materials and Design 60 (2014) 628-636. 
[20] B.-Y. Chen, K.-S. Hwang, K.-L. Ng, Effect of Cooling Process on the Alpha Phase Formation and Mechanical Properties of Sintered Ti-Fe Alloys, Materials Science and Engineering: A 528 (2011) 4556-4563.

[21] K. Molchanova, Phase Diagrams of Titanium Alloys, Translation of Atlas Diagram (Sostoyaniya Titanovyk Splavov), Israel Program for Scientific Translations, Jerusalem (1965) 154.

[22] ASTM E1409, Standard Test Method for Determination of Oxygen in Titanium and Titanium Alloys by the Inert Gas Fusion Technique, 2008.

[23] ASTM B331, Standard Test Method for Compressibility of Metal Powders in Uniaxial Compaction, 2010.

[24] ASTM B312, Standard Test Method for Green Strength for Compacted Metal Powder Specimens, 2009.

[25] ASTM B528, Standard Test Method for Transverse Rupture Strength of Metal Powders Specimens, 2005.

[26] L. Bolzoni, P.G. Esteban, E.M. Ruiz-Navas, E. Gordo, Mechanical Behaviour of Pressed and Sintered Titanium Alloys Obtained from Prealloyed and Blended Elemental Powders, Journal of the Mechanical Behavior of Biomedical Materials 14 (2012) 29-38.

[27] F.H. Froes, D. Eylon, Powder Metallurgy of Titanium Alloys - A Review, Powder Metallurgy International 17(4) (1985) 163-167.

[28] F.H. Froes, D. Eylon, Powder Metallurgy of Titanium Alloys - A Review, Powder Metallurgy International 17(5) (1985) 235-238.

[29] W. Schatt, K.-P. Wieters, Powder Metallurgy. Processing and Materials, EPMA - European Powder Metallurgy Association, Shrewsbury, UK, 1997. 
[30] R.M. German, Powder Metallurgy of Iron and Steel, John Wiley \& Sons, Inc., New York, 1998.

[31] R. Boyer, G. Welsch, E.W. Collings, Materials Properties Handbook: Titanium Alloys, ASM International, Ohio, USA, 1998.

[32] L. Bolzoni, I. Montealegre Meléndez, E.M. Ruiz-Navas, E. Gordo, Microstructural Evolution and Mechanical Properties of the Ti-6Al-4V Alloy Produced by Vacuum Hotpressing, Materials Science and Engineering A 546 (2012) 189-197.

[33] H. Nakajima, K. Yusa, Y. Kondo, Diffusion of Iron in a Diluted [Alpha]-Ti-Fe Alloy, Scripta Materialia 34(2) (1996) 249-253.

[34] H. Nakajima, S. Ohshida, K. Nonaka, Y. Yoshida, F.E. Fujita, Diffusion of Iron in [Beta] Ti-Fe Alloys, Scripta Materialia 34(6) (1996) 949-953.

[35] T.M.T. Godfrey, A. Wisbey, P.S. Goodwin, K. Bagnall, C.M. Ward-Close, Microstructure and Tensile Properties of Mechanically Alloyed Ti-6Al-4V with Boron Additions, Materials Science and Engineering A 282(1-2) (2000) 240-250.

[36] F.H. Froes, O.M. Ivasishin, V.S. Moxson, D.G. Savvakin, K.A. Bondareva, A.M. Demidik, Cost-effective Synthesis of Ti-6Al-4V Alloy Components via the Blended Elemental P/M Approach, in: W. TMS, PA (Ed.) Symposium on TMS Symposium on High Performance Metallic Materials for Cost Sensitive Applications, Seattle, WA, 2002.

[37] V.S. Moxson, J.I. Qazi, S.N. Patankar, O.N. Senkov, F.H. Froes, Low-cost CP-titanium and Ti-6Al-4V Alloys, Advanced Materials Forum I 230-2 (2002) 339-343.

[38] R.I. Jaffee, I.E. Campbell, The Effect of Oxygen, Nitrogen and Hydrogen on Iodide Refined Titanium, Transactions of the American Institute of Mining and Metallurgical Engineers 185(9) (1949) 646-654. 
[39] R.I. Jaffee, H.R. Ogden, D.J. Maykuth, Alloys of Titanium with Carbon, Oxygen and Nitrogen, Transactions of the American Institute of Mining and Metallurgical Engineers 188(10) (1950) 1261-1266.

[40] W.L. Finlay, J.A. Snyder, Effects of Three Interstitial Solutes (Nitrogen, Oxygen and Carbon) on the Mechanical Properties of High-purity Alpha Titanium, Journal of Metals 188 (1950) 277-286.

[41] D. Henry, Materials and Coatings for Medical Devices: Cardiovascular, ASM International, Ohio, USA, 2009. 